Revista Multidisciplinar do Nordeste Mineiro, v.2,

\title{
A ERGONOMIA NO POSICIONAMENTO CORPORAL EM CICLISTAS AMADORES
}

\section{ERGONOMICS IN BODY POSITIONING IN AMATEUR CYCLISTS: A}

\section{BIBLIOGRAPHIC REVIEW}

\author{
Karolayne Lubarino da Silva \\ Leonardo Squinello Nogueira Veneziano
}

Fernando Duarte Cabral

Renato Canevari Dutra da Silva

A ergonomia no posicionamento corporal em ciclistas amadores, UNIBRÁS Faculdade de Rio Verde, Brasil.

E-mail: karolaynelubarino@gmail.com

Recebido: 15/06/2021 - Aceito: 20/06/2021

\section{Resumo}

A ergonomia pode influenciar no posicionamento e na prevenção de lesões musculoesqueléticas na prática do ciclismo em atletas amadores, através de orientações para correção da postura e preparo físico, afim, de evitar complicações tardias e fadiga muscular. Assim como, pode interferir no tamanho e regulagem da bicicleta. Objetivos: avaliar a influência da ergonomia na postura dos ciclistas, 
investigar lesões musculoesqueléticas que possam surgir diante da prática incorreta e buscar modelos e avaliações ergonômicas para o ajuste da bicicleta. Metodologia: avaliação postural dos ciclistas, através do Método RULA (RAPID UPPER LIMB ASSESSMENT) e o método OWAS Ovako Working Posture. Analysis System). Referencial teórico: interagir com um produto como a bicicleta, requer o desenvolvimento e/ou aprimoramento de certas capacidades. Essa atividade física requer, por parte do usuário e após a percepção das condições de uso, da realização de ajustes constantes. Considerações finais: através das avaliações posturais e os métodos utilizados podemos ver que é de suma importância a ergonomia na relação ciclista-bicicleta, principalmente para a prevenção de lesões decorrentes.

Palavras-chave: ergonomia; ciclismo; postura; bicicleta;

\section{Abstract}

Ergonomics can influence the positioning and prevention of musculoskeletal injuries in the practice of cycling in amateur athletes, through guidelines for correcting posture and physical preparation, in order to avoid late complications and muscle fatigue. As well, it can interfere with the size and regulation of the bicycle. Objectives: to evaluate the influence of ergonomics on the cyclists' posture, to investigate musculoskeletal injuries that may arise in the face of incorrect practice and to seek models and ergonomic evaluations for the adjustment of the bicycle. Methodology: postural assessment of cyclists, using the RULA Method (RAPID UPPER LIMB ASSESSMENT) and the OWAS Ovako Working Posture. Analysis System) method. Theoretical framework: interacting with a product such as a bicycle, requires the development and / or improvement of certain capabilities. This physical activity requires, on the part of the user and after realizing the conditions of use, constant adjustments to be made. Final considerations: through the postural evaluations and the methods used we can see that ergonomics in the cyclist-bicycle relationship is of paramount importance, mainly for the prevention of injuries arising.

Keywords: ergonomics; cycling; posture; bicycle; 


\section{Introdução}

A ergonomia pode influenciar no posicionamento e na prevenção de lesões musculoesqueléticas na prática do ciclismo em atletas amadores, através de orientações para correção da postura e preparo físico, afim, de evitar complicações tardias e fadiga muscular. Assim como, pode interferir no tamanho e regulagem da bicicleta.

A bicicleta tanto pode ser utilizada como veículo de eleição para o deslocamento ao trabalho, como para atividades de lazer, reabilitação, treinamento físico buscando qualidade de vida e também de forma profissional por atletas em treinamento e atividades competitivas (CARMO et al., 2001).

A prática incorreta do ciclismo pode acarretar diversas consequências para o sistema musculoesquelético. Dessa forma, por falta de informação, atletas amadores praticam em um posicionamento errado, e assim, ocasiona lesões futuras.

Na utilização da bicicleta todo um conjunto de músculos entra em atividade e se o indivíduo não se posicionar corretamente irá sentir, em curto período, cansaço muscular (ARAUJO; RAMOS; SILVA, 2006).

Os aspectos relacionados à ergonomia, nesse caso, dizem respeito ao ajuste correto da interação ciclista-bicicleta na busca tanto por conforto como por desempenho e bem-estar (KLEINPAUL et al., 2010).

Interagir com um produto como a bicicleta, requer o desenvolvimento e/ou aprimoramento de certas capacidades. Essa atividade física requer, por parte do usuário e após a percepção das condições de uso, da realização de ajustes constantes e em simultâneo. Assim tem-se o equilíbrio corporal, avaliação dinâmica e espacial dos acontecimentos (em velocidades variáveis e diferentes das obtidas na ação de simples caminhar) além de uma predisposição a "tolerar" a influência climática (DIBAN; MERINO; GONTIJO, 2016). 
No ciclismo o estudo da ergonomia auxilia na adequação da bicicleta às características físicas do praticante, a fim de encontrar um equilíbrio de ajuste para otimização da performance na atividade, favorecendo a prevenção de lesões (HAYOT et al., 2012).

Este trabalho possui como objetivo avaliar a influência da ergonomia na postura dos ciclistas, investigar lesões musculoesqueléticas que possam surgir diante da prática incorreta e buscar modelos e avaliações ergonômicas para o ajuste da bicicleta. Sendo assim, utilizar medidas que sejam ideais para o conforto e segurança para o individuo na prática do ciclismo.

\section{Revisão Bibliográfica}

A Ergonomia, conforme Ferreira (2011), tem a função de gerar o desenvolvimento das situações de trabalho, tanto nos aspectos materiais, quanto nas ferramentas sociais e organizacionais, obtendo o objetivo maior de saúde, segurança, conforto, satisfação e eficácia no desempenho das atividades do trabalhador.

Assim sendo, pode-se perceber o quão importante é a ergonomia dentro das organizações, sejam elas empresas, indústrias, comércios e serviços. Também existem as casas e lares, escolas, creches, igrejas, etc., que mesmo não configurando uma situação de trabalho remunerado demandam tarefas e atividades a serem desenvolvidas, ou seja, existe a interação entre o homem e o sistema de realização da tarefa. Dessa forma, pode-se dizer que qualquer que seja o trabalho ou atividade realizado pelo homem, seja esse remunerado ou não, o mesmo pode, de alguma maneira, ser beneficiado com a aplicação da ergonomia (MENDES; MACHADO, 2016).

A Ergonomia (ou Fatores Humanos) é uma disciplina científica relacionada ao entendimento das interações entre os seres humanos e outros elementos ou sistemas, e à aplicação de teorias, princípios, dados e métodos a projetos a fim de otimizar o bem estar humano e o desempenho global do sistema. Os ergonomistas 
contribuem para o planejamento, projeto e a avaliação de tarefas, postos de trabalho, produtos, ambientes e sistemas de modo a torná-los compatíveis com as necessidades, habilidades e limitações das pessoas (IEA - Associação Internacional de Ergonomia, 2000).

O objeto de estudo é a interação entre o homem e o trabalho no sistema homem-máquina-ambiente, ou mais precisamente, as interfaces desse sistema, onde ocorrem trocas de informações e energias entre o homem, máquina e ambiente, resultando na realização do trabalho (IIDA, 2005).

É o estudo das interações das pessoas com a tecnologia, a organização e o ambiente, objetivando intervenções e projetos que visem melhorar, de forma integrada e não dissociada, a segurança, o conforto, o bem-estar e a eficácia das atividades humanas (MOREIRA, et al., 2017).

A Ergonomia estuda a postura humana que é a relação entre as posições dos complexos articulares do corpo em um dado momento. Em um alinhamento postural ideal, espera-se que os músculos, articulações e suas estruturas esqueléticas encontrem-se em estado de equilíbrio dinâmico, gerando uma quantidade mínima possível de esforço e sobrecarga, na qual o aparelho locomotor tenha máxima eficiência (CANEDO; SILVA; JUNNIOR, 2017).

No ciclismo, a ergonomia tem como objetivo principal aumentar a segurança, a satisfação e o bem-estar dos ciclistas, isto é, procura adaptar a bicicleta à estrutura humana para que se alcance o melhor rendimento na pedalada (PEQUINI, 2000).

Seu objetivo é elaborar, mediante a contribuição de diversas disciplinas científicas que a compõem, um corpo de conhecimentos que, dentro de uma perspectiva de aplicação, deve resultar em uma melhor adaptação ao homem dos meios tecnológicos, dos ambientes de trabalho e de vida (International Ergonomics Association - IEA, 2000).

O ciclismo é uma modalidade de atividade física e desporto amplamente difundida e com impacto socioeconómico elevado. Todavia, tal e qual outras modalidades não está isenta de lesões, exigindo, por essa razão, a intervenção de 
equipas de saúde e muito particularmente da fisioterapia (KOTLER; BABU; ROBIDOUX, 2016).

Nas últimas décadas, a popularidade do uso da bicicleta nos desportos e nas atividades recreativas proporcionou mudanças e inovações formais deste produto, na busca de minimizar danos físicos, aumentar o conforto e o prazer por parte do usuário deste produto, com isso surgiram novos estilos e modelos diferentes do produto, com sistemas de suspensão e o emprego de novos materiais (ARAUJO; RAMOS; SILVA, 2006).

Interagir com um produto como a bicicleta, requer o desenvolvimento e/ou aprimoramento de certas capacidades. Essa atividade física requer, por parte do usuário e após a percepção das condições de uso, da realização de ajustes constantes e em simultâneo. Assim tem-se o equilíbrio corporal, avaliação dinâmica e espacial dos acontecimentos (em velocidades variáveis e diferentes das obtidas na ação de simples caminhar) além de uma predisposição a "tolerar" a influência climática (DIBAN; MERINO; GONTIJO, 2016).

O ciclismo é uma atividade esportiva de muito baixo impacto cuja facilidade em adquirir condicionamento cardiovascular tem motivado, mais do que qualquer outro esporte, as pessoas a começarem a pedalar. Paralelo ao aumento na popularidade do ciclismo tem-se observado uma incidência crescente dos traumas relacionados à sua prática, especialmente, em ciclistas que negligenciam o uso de equipamento de segurança e os riscos de queda (ALENCAR; MATIAS; AGUIAR, 2012).

Há um aumento significativo de pessoas que tem se organizado em grupos para a prática esportiva, entre elas o ciclismo amador, que recebe várias denominações como grupos de pedalada, grupos de pedal, grupos de bicicleta, entre outras, que visam buscar práticas mais saudáveis de vida. Porém, muitas vezes esses grupos realizam tais atividades sem a orientação de um profissional da área da saúde, levando os participantes a utilizar a bicicleta sem preparo físico, ficando expostos aos riscos de lesões osteomioarticulares (NUNES; FONSECA, 2017). 
O prazer proporcionado pela atividade de andar de bicicleta perde-se muitas vezes devido ao mau posicionamento na bicicleta, proporcionando dores nas costas, no pescoço ou nos joelhos, podendo ir mesmo ao ponto do adormecer das mãos. Buscar um posicionamento adequado apresenta vantagens para o ciclista como evitar lesões e dores crônicas, através de pesquisas de biomecânica (ARAUJO; RAMOS; SILVA, 2006).

A avaliação postural tem importância fundamental para o diagnóstico, planejamento e acompanhamento da evolução de um tratamento fisioterapêutico, porém é uma avaliação complexa, difícil de mensurar (CANEDO; SILVA; JUNNIOR, 2017).

A altura da sela é fator importante para se conseguir uma posição confortável, se estiver muito alto o ciclista corre o risco de esticar em demasia os músculos e se estiver muito baixo a pressão nos quadríceps pode torna-se demasiado alta (ARAUJO; RAMOS; SILVA, 2006).

Muitas vezes o ajuste da bicicleta ainda é feito numa base de tentativa e erro. Ajustes incorretos no posicionamento podem levar à lesão, pois podem acarretar aumento da sobrecarga músculo-esquelética (BURKE, 1996).

O método RULA (RAPID UPPER LIMB ASSESSMENT) é um método de avaliação postural, no qual se utiliza de diagramas para a avaliação dos membros superiores e inferiores. As posturas exercidas nos postos de trabalho são enquadradas de acordo com as angulações entre os membros e o corpo (CANEDO; SILVA; JUNNIOR, 2017).

Tem como finalidade investigar a exposição sofrida por trabalhadores durante a atividade laboral, de fatores de risco. O método usa diagramas das posturas do corpo e três escores que permitem a avaliação da exposição aos fatores de risco (MOREIRA, et al., 2017).

O sistema OWAS é uma ferramenta ergonômica prática. Seus desenvolvedores foram três pesquisadores finlandeses que trabalhavam em uma siderúrgica: Karku, Kansi e Kuorinka, no ano de 1977. O começo se deu através de análise fotográfica das posturas principais, as quais podiam ser observadas em 
Revista Multidisciplinar do Nordeste Mineiro, v.2,

2021/02

ISSN 2178-6925

indústrias pesadas, sendo encontradas 72. Esse número é resultante de diferentes combinações de dorso, braços e pernas (IIDA, 2005).

O método se baseia na amostragem das atividades em intervalos constantes ou variáveis, verificando-se a frequência e o tempo gasto em cada postura. Nas amostragens são consideradas as posturas das costas, braços, pernas, uso de força e fase da atividade. Os autores do método sugerem que sejam realizadas no mínimo 100 observações para que se possa inferir corretamente sobre a tarefa analisada (MOREIRA, et al., 2017).

\section{Considerações Finais}

Sendo assim, podemos concluir que a postura e a regulagem da bicicleta são fatores que influenciam no posicionamento correto dos atletas amadores. Dessa forma, através das avaliações posturais e os métodos utilizados podemos ver que é de suma importância a ergonomia na relação ciclista-bicicleta, principalmente para a prevenção de lesões decorrentes.

\section{Referências}

ALENCAR, T. A. M.; MATIAS, K. F. S.; AGUIAR, B. C. Lesões agudas em ciclistas. Revista movimenta, v.5 n.3, 2012.

ARAUJO, I. F.; RAMOS, J. A.; SILVA, W. R. Avaliação ergonômica do sistema bicicleta-usuário do modelo Barra Circular da Monark. XXVI ENEGEP. Fortaleza: 2006.

BURKE, E. R.; PRUITT, A. L. Body positioning for cycling. High-Tech Cycling. Champaign: Ed. Human Kinetics, p. 69-92, 2003. 
CANEDO, G. R.; SILVA, B. C.; JUNNIOR, R.C.D. Aplicação do método rula (rapid upper limb assessment) em um laboratório didático. ABEPRO Associação brasileira e engenharia e produção, 2017.

CARMO, J. D. et al. Instrumentação para aquisição e avaliação das forças exercidas nos pedais por ciclistas. Revista Brasileira de Biomecânica, v. 2, n. 3, p. 31-37, 2001.

DIBAN, D. O. N.; MERINO, E. A. D.; GONTIJO, L. A. Contribuição da Ergonomia no Processo de Desenvolvimento de Produto: 0 Caso do Selim de bicicletas. Revista HFD, v.2 n.3, p 3 - 17, 2013.

GÜÉRIN, F. et al. Compreender o trabalho para transformá-lo: a prática da ergonomia. São Paulo: Edgard Blucher, 2001.

IEA - Associação Internacional de Ergonomia. Abergo: associação brasileira de ergonomia, 2000.

IIDA, I. Ergonomia: projeto e produção. São Paulo: Edgard Blücher, 2005.

KLEINPAUL, J. F. et al. Aspectos determinantes do posicionamento corporal no ciclismo: uma revisão sistemática. Revista de Educação física, Rio Claro, v.16, n.4, p.1013-1023, out./dez, 2010. 
KOTLER, D. H.; BABU, A. N.; ROBIDOUX, G. Prevention, evaluation, and rehabilitation of cycling-related injury. Current sports medicine reports. v. 3 p. 199-206, 2016.

MENDES, T.Z.; MACHADO, R. L. Análise ergonômica do trabalho: a ergonomia auxiliando na melhoria contínua do trabalho do homem. Estudo ergonômico sobre um posto de trabalho de uma indústria do ramo moveleiro. ABEPRO Associação brasileira de engenharia de produção, 2016.

MOREIRA, T. et al. Análise ergônomica: métodos rula e aplicados em uma instituição de ensino superior. Revista Espacios, v. 38, n. 11, p. 22, 2017.

PEQUINI, M. P. A evolução tecnológica da bicicleta e suas implicações ergonômicas para a máquina humana: problemas da coluna vertebral $x$ bicicletas dos tipos Speed e Mountain Bike. Dissertação (Programa de PósGraduação em Arquitetura e Urbanismo). Universidade de São Paulo. Instituto de Gestão de Desenvolvimento de Produtos. São Paulo, 2000.

NUNES, K.; FONSECA, P. S. A prevalência de lesões osteomioarticulares em ciclistas amadores. Unicesumar - centro universitário de maringá, 2017. 
Revista Multidisciplinar do Nordeste Mineiro, v.2,

2021/02

ISSN 2178-6925 
Revista Multidisciplinar do Nordeste Mineiro, v.2,

2021/02

ISSN 2178-6925 
Revista Multidisciplinar do Nordeste Mineiro, v.2,

2021/02

ISSN 2178-6925 
Revista Multidisciplinar do Nordeste Mineiro, v.2,

2021/02

ISSN 2178-6925 